\title{
Hura crepitans Seed Oil: An Alternative Feedstock for Biodiesel Production
}

\author{
Adewale Adewuyi, ${ }^{1}$ Paul O. Awolade, ${ }^{2}$ and Rotimi Ayodele Oderinde ${ }^{2}$ \\ ${ }^{1}$ Department of Chemical Sciences, Faculty of Natural Sciences, Redeemer's University, Redemption City, Ogun State, Nigeria \\ ${ }^{2}$ Industrial Unit, Department of Chemistry, University of Ibadan, Ibadan, Oyo State, Nigeria
}

Correspondence should be addressed to Adewale Adewuyi; walexy62@yahoo.com

Received 12 June 2014; Accepted 22 July 2014; Published 10 August 2014

Academic Editor: Xingcai Lu

Copyright (C) 2014 Adewale Adewuyi et al. This is an open access article distributed under the Creative Commons Attribution License, which permits unrestricted use, distribution, and reproduction in any medium, provided the original work is properly cited.

\begin{abstract}
Oil was extracted from the seed of Hura crepitans using hexane in a soxhlet extractor and analyzed for iodine value, saponification value and free fatty acid content. The dominant fatty acid in the oil was C18:2 (52.8 $\pm 0.10 \%)$ while the iodine value was $120.10 \pm$ $0.70 \mathrm{~g}$ iodine $/ 100 \mathrm{~g}$. Biodiesel was produced from the oil using a two-step reaction system involving a first step of pretreatment via esterification reaction and a second step via transesterification reaction. The pretreatment step showed that free fatty acid in Hura crepitans seed oil can be reduced in a one-step pretreatment of esterification using $\mathrm{H}_{2} \mathrm{SO}_{4}$ as catalyst. The biodiesel produced from Hura crepitans seed oil had an acid value of $0.21 \pm 0.00 \mathrm{mg} \mathrm{KOH} / \mathrm{g}$, flash point of $152 \pm 1.10^{\circ} \mathrm{C}$, copper strip corrosion value of $1 \mathrm{~A}$, calorific value of $39.10 \pm 0.30 \mathrm{~mJ} / \mathrm{kg}$, cetane number of $45.62 \pm 0.30$, and density of $0.86 \pm 0.02 \mathrm{~g} \mathrm{~cm}^{-3}$. The process gave a biodiesel yield of $98.70 \pm 0.40 \%$ with properties within the recommended values of EN 14214 .
\end{abstract}

\section{Introduction}

Rapid diminishing of energy reserves and fluctuating petroleum prices have intensified the search for renewable energy sources [1]. Biodiesel is an alternative diesel fuel consisting of fatty acid alkyl esters obtained from vegetable oil or animal fats. It is renewable, reduces the emission of some pollutants, and is also readily biodegradable in the environment $[2,3]$.

Currently, more than $95 \%$ of world biodiesel is produced from edible oils (e.g., soyabean, rapeseed, canola, cotton, palm, and palm kernel oils) which are easily available in a large scale from the agricultural industry [4] but considering the daily rise in human population, this has brought some short comings as the human population faces serious food shortages and malnutrition arising from the extensive use of these edible oils for fuel and as a result drawing attention towards the inedible oils is imperative. Inedible oils (or cheap oils) generally have higher free fatty acid (FFA) content compared to edible oils; thus a pretreatment step is often required to reduce the FFA content to a workable level. A bulky part of the cost incurred in the production of biodiesel comes from the cost of the feedstock which accounted for 75$88 \%$ of the total production cost $[5,6]$.

Agriculturally derived feedstocks such as vegetable oils are important in the long-term vision of providing secured, cost effective, and clean sources of energy for Nigeria and other nations of the world. Vegetable oils have attracted attention as a potential renewable resource for the production of an alternative for petroleum-based diesel fuel [7-9]. The various products derived from vegetable oils have been proposed as alternative fuels for diesel engines, including neat vegetable oil, mixtures of vegetable oil with petroleum diesel, and esters of vegetable oils [10]. According to Korus et al. [9], biodiesel appears to be the most promising alternative. The advantages of using biodiesel compared to mineral-derived diesel fuel include reduced exhaust emissions, promising alternative of mineral based diesel fuel, improved biodegradability, reduced toxicity and improved lubricity, higher flash point, and lower vapour pressure [11, 12]. High oil prices and the need to reduce greenhouse gas emissions make investment in biofuels desirable [13]. According to Scarisbrook and Ferguson [14], the most important advantage, which may well become the dominant factor with the passage of time, is the fact that such 
TABLE 1: Chemical properties of Hura crepitans seed oil.

\begin{tabular}{lc}
\hline Parameters & Hura crepitans \\
\hline Yield $(\%)$ & $37.75 \pm 0.40$ \\
Acid value $(\mathrm{mg} \mathrm{KOH} / \mathrm{g})$ & $4.41 \pm 0.20$ \\
Iodine value $(\mathrm{g}$ iodine $/ 100 \mathrm{~g})$ & $120.10 \pm 0.70$ \\
Saponification value $(\mathrm{mg} \mathrm{KOH} / \mathrm{g})$ & $210.10 \pm 0.40$ \\
\hline
\end{tabular}

Values are mean \pm standard deviation of triplicate determinations.

biofuels have a positive energy balance. By positive energy balance, it is meant that the energy used in the production of the fuel is less than the energy value of the fuel produced together with many of the associated utilized byproducts. The use of cheap and nonedible seed oils, animal fats, and waste oils as raw feedstocks for biodiesel production is an effective way to reduce the cost of biodiesel. So, the search for nonedible underutilized seed oils as feedstock for producing biodiesel is important.

Hura crepitans is an underutilized plant in Nigeria, which is planted as a shade tree in villages and towns. It is a dicotyledon belonging to the Euphorbiaceae family (spurge family). It is an evergreen perennial tree native to tropical regions of North and South America in Amazon rainforest and is also known as sandbox tree, possum wood, and jabillo. The tree prefers wet soil and is often planted for shade. It is recognized by the many dark and pointed spines, smooth brown bark, and spreading branches. Hura crepitans can grow to $30 \mathrm{~m}(100 \mathrm{ft})$. It has large ovate leaves which grow to $2 \mathrm{ft}$ wide. They are monoecious, long stemmed, heart shaped, and papery thin. The physicochemical properties of Hura crepitans have been reported $[15,16]$. Presently, there is no specific use of the oil of Hura crepitans in Nigeria, as the seeds are discarded as waste since they have no specific use at present. Some of the properties of this oil have been reported in our previous study [17]; the most abundant fatty acid was reported to be C18:2 as shown in Table 1.

The present work evaluated the production of biodiesel from the seed oil of Hura crepitans. Biodiesel from seed oil of Hura crepitans was recently reported by Igbum et al. [18] but this was not in detail as some important properties were not evaluated; moreover, the production method reported in the present study is different from what was reported by Igbum et al. The present method involved an acid catalyzed pretreatment step in order to reduce the free fatty acid content of the oil thus preventing the formation of emulsion usually encountered during production when seed oils with some level of free fatty acid content are used. The production of the biodiesel was monitored and confirmed using ${ }^{1} \mathrm{HNMR}$ and ${ }^{13}$ CNMR.

\section{Materials and Methods}

2.1. Materials and Sample Preparation. Ripe and dry undehisced pods of Hura crepitans were picked from trees grown within the premises of the campus of University of Ibadan, Nigeria, and identified at the Herbarium Unit of the Department of Botany, University of Ibadan, Nigeria. The seeds were carefully removed from the pods while the endocarp was gently removed to get the creamy white cotyledons inside which were dried in a Memmert oven set to a constant temperature of $105^{\circ} \mathrm{C}$. Finally, the dry cotyledons were ground and stored for extraction. All solvents and chemicals used in this study were of analytical grade and were purchased from Sigma-Aldrich, Germany.

\subsection{Extraction and Fatty Acid Composition of Hura crepitans} Seed Oil. Oil was extracted from the seed of Hura crepitans using soxhlet extractor with $n$-hexane for $10 \mathrm{~h}$ [19]. The iodine value, saponification value, and acid value of the oil were determined by methods described by the Association of Official Analytical Chemist [20]. Fatty acid methyl ester of the oil was prepared by refluxing the oil at $70^{\circ} \mathrm{C}$ for $3 \mathrm{~h}$ in $2 \%$ sulphuric acid in methanol. The ester was extracted into ethyl acetate, washed free of acid, and passed over anhydrous sodium sulphate. The ethyl acetate extract was further concentrated using a rotary evaporator. The fatty acid composition was analyzed using an Agilent $6890 \mathrm{~N}$ series gas chromatography equipped with FID detector on a split injector. A fused silica capillary column (DB-225, $30 \times$ $0.32 \mathrm{~m}$ i.d., J\&W Scientifics, USA) was used with the injector and detector temperature maintained at $230^{\circ} \mathrm{C}$ and $250^{\circ} \mathrm{C}$, respectively. The oven temperature was programmed at $160^{\circ} \mathrm{C}$ for $2 \mathrm{~min}$ and finally increased to $230^{\circ} \mathrm{C}$ at $4^{\circ} \mathrm{C} / \mathrm{min}$. The carrier gas was nitrogen at a flow rate of $1.5 \mathrm{~mL} / \mathrm{min}$. The area percentages were recorded with a standard Chemstation Data System.

2.3. Biodiesel from the Seed Oil of Hura crepitans. The oil of Hura crepitans was converted to biodiesel using a one-step pretreatment of $2 \%$ sulphuric acid in methanol in order to reduce the free fatty acid content of the oil which may lead to soap formation during the process of biodiesel production. To achieve this, the oil was firstly degummed using $2 \%$ water in oil in a centrifuge at $1800 \mathrm{rpm}$ for $45 \mathrm{~min}$. The degummed oil was later esterified using $2 \%$ sulphuric acid in methanol at $70^{\circ} \mathrm{C}$. The esterification was carried out for $3 \mathrm{~h}$ and the progress of the reaction was monitored using TLC to check the conversion of the free fatty acids to methyl esters using hexane-ethyl acetate $(95: 10, \mathrm{v} / \mathrm{v})$ as developing solvent. The eluted spots on the TLC plate were identified using iodine vapors. The esterified oil was finally transesterified to biodiesel at $70^{\circ} \mathrm{C}$ for $6 \mathrm{~h}$ using methanol at a molar ratio of $1: 6$ (oil : methanol) in the presence of $\mathrm{KOH}$ (1\% of total weight) as catalyst. The biodiesel formed was extracted with ethyl acetate, washed free of $\mathrm{KOH}$ using distilled water, dried over sodium sulphate, and concentrated in a rotary evaporator.

Figures 1(a) and 1(b) present the equation of reaction for the esterification and transesterification of Hura crepitans seed oil. The \% efficiency of the process was calculated as follows [21]:

$$
\% \text { Efficiency }=\frac{A_{i}-A_{f}}{A_{i}} \times 100,
$$

where $A_{i}=$ initial \% FFA of oil before pretreatment and $A_{f}=$ final $\%$ FFA after pretreatment. 


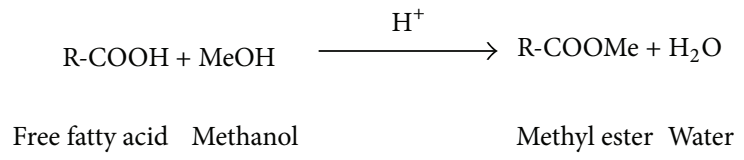

(a)

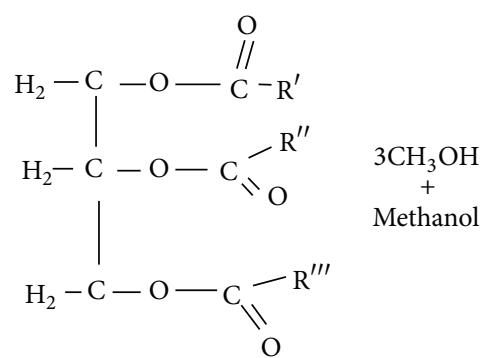

Triglyceride<smiles>[R]C(=O)OC</smiles>

Glycerol
Biodiesel

(b)

Figure 1: (a) Pretreatment of Hura crepitans oil with 2\% sulphuric acid in methanol. (b) Transesterification of Hura crepitans oil to biodiesel.

2.4. Nuclear Magnetic Resonance (NMR) Spectroscopy. ${ }^{1} \mathrm{HNMR}$ and ${ }^{13} \mathrm{CNMR}$ spectra of the oil, pretreated oil (esterified oil), and biodiesel of Hura crepitans were obtained on a 300 and $75 \mathrm{MHz}$ Bruker NMR spectrophotometer.

2.5. Properties of the Biodiesel. The biodiesel produced was analyzed using standard procedures. Viscosity was determined as described by the standard method of the American Society for Testing and Material [22]. The biodiesel produced was separated on a $1 \mathrm{~g}$ scale into methyl esters, triglycerides, diglycerides, monoglycerides, and free fatty acids by silica gel column chromatography using a glass column $20 \mathrm{~cm} \times 2 \mathrm{~cm}$ OD packed with $30 \mathrm{~g}$ activated silica gel (60-120 mesh) [23]. The cetane number of the methyl esters was calculated using the following [24]:

$$
\mathrm{CN}=46.3+\frac{5458}{\mathrm{SV}}-(0.225 \times \mathrm{IV}),
$$

where $\mathrm{CN}$ = cetane number, $\mathrm{SV}$ = saponification value, and $\mathrm{IV}=$ iodine value. The calorific value of the biodiesel was calculated by the approximate equation [25]. Consider

$$
\mathrm{H}_{\mathrm{u}}=47,645-4.187 \mathrm{I}-38.31 \mathrm{~S} \text { in } \mathrm{KJ} / \mathrm{Kg} \text {, }
$$

where I and S are the iodine and saponification values of the biodiesel, respectively. The iodine value was determined by method described by the Association of Official Analytical Chemist [20] while density was determined at $15^{\circ} \mathrm{C}$. The biodiesel oxidative stability index (OSI) was measured in accordance with EN 14112 [26] employing a Rancimat. Determination of copper corrosion test was carried out using the method described by the standard method of the American Society for Testing and Material (ASTM, D396) [27] while flash point was determined using the AOCS modified method for closed cup flash point determination [28].
TABLE 2: Fatty acid composition (wt\%) of Hura crepitans seed oils [17].

\begin{tabular}{lc}
\hline Fatty acids & Hura crepitans \\
\hline $16: 0$ & $12.20 \pm 0.20$ \\
$16: 1$ & $0.10 \pm 0.00$ \\
$18: 0$ & $5.1 \pm 0.30$ \\
$18: 1$ & $27.2 \pm 0.20$ \\
$18: 2$ & $52.8 \pm 0.10$ \\
$18: 3$ & $1.8 \pm 0.10$ \\
$20: 0$ & $0.2 \pm 0.10$ \\
$20: 1$ & $0.3 \pm 0.10$ \\
$22: 0$ & $0.3 \pm 0.10$ \\
Unsaturated & $82.2 \pm 0.20$ \\
Saturated & $17.80 \pm 0.20$ \\
\hline
\end{tabular}

Values are mean \pm standard deviation of triplicate determinations.

\section{Results and Discussion}

3.1. Extraction and Fatty Acid Composition of Hura crepitans Seed Oil. The dominant fatty acid in the oil has been reported by Adewuyi et al. [17] to be C18:2 (52.8 $\pm 0.10 \%)$ as shown in Table 1 . The oil yield was $37.75 \pm 0.40 \%$ as presented in Table 2. The yield of oil from the seed of Hura crepitans is relatively high when compared with those of other oil bearing seeds [29]; this relatively high oil content of the seed presents the seed of Hura crepitans as a good source of oil making it economically viable and at present the seed is discarded as waste with no market value.

3.2. Nuclear Magnetic Resonance (NMR) Spectroscopy. The formation of the biodiesel was monitored using NMR. Figure 2 presents the ${ }^{1} \mathrm{HNMR}$ spectrum of the oil, esterified oil, and biodiesel. 


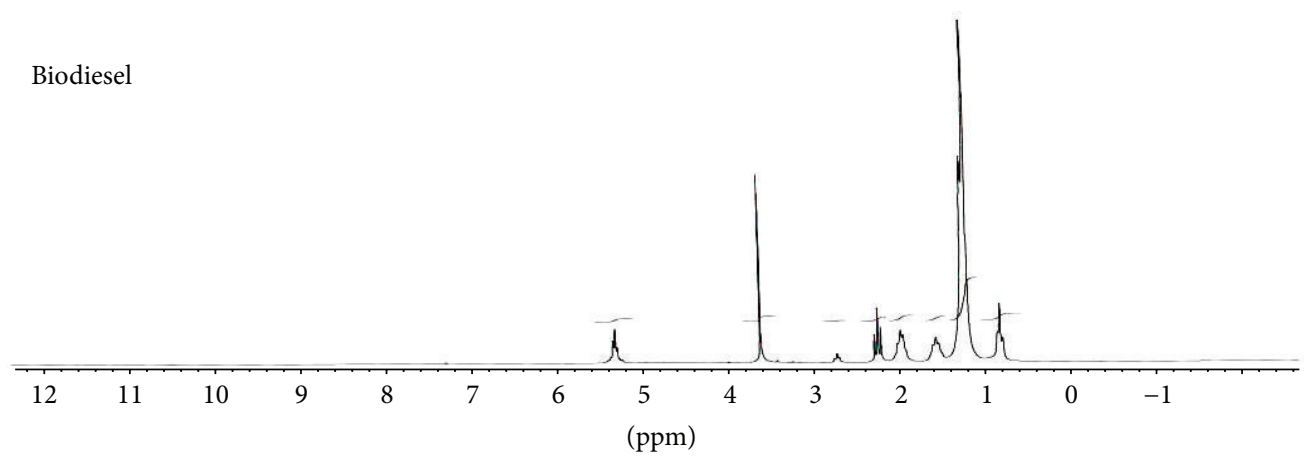

(a)

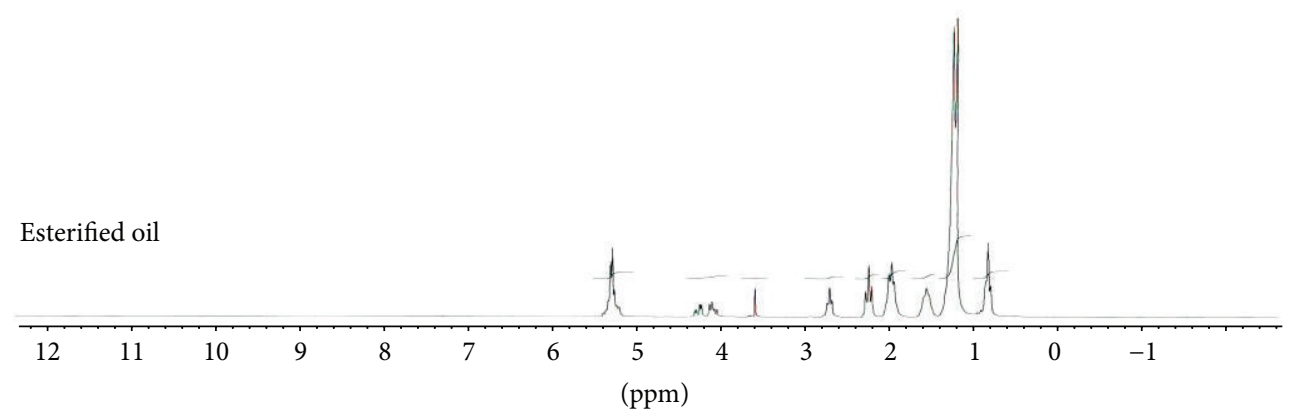

(b)

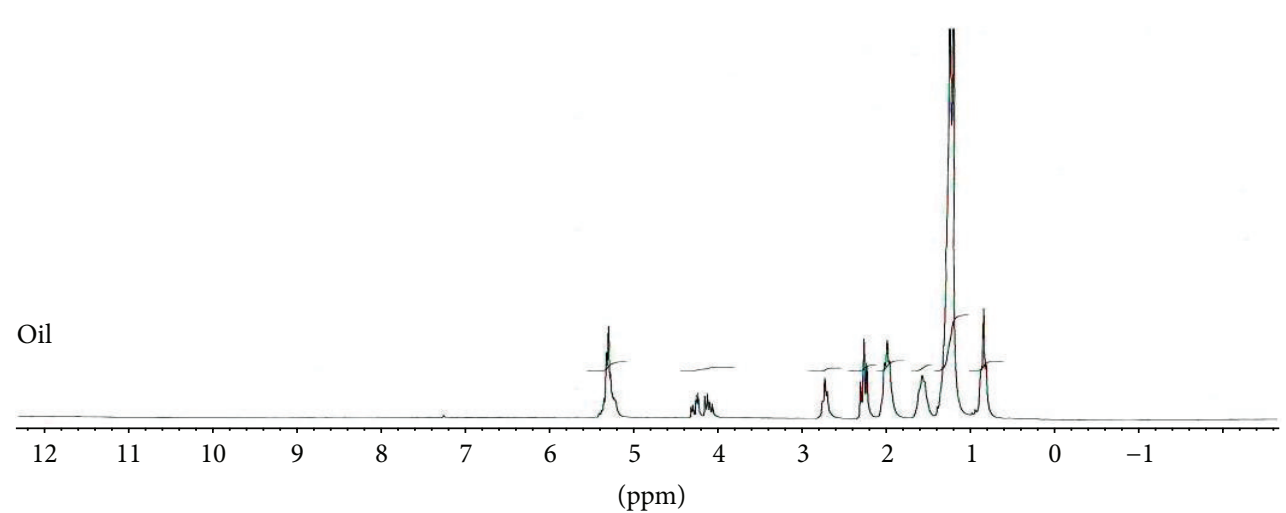

(c)

Figure 2: ${ }^{1}$ HNMR spectra of oil, esterified oil, and biodiesel.

The spectrum revealed peaks at around $0.88,1.25$, and $1.6 \mathrm{ppm}$ which were assigned to the terminal methyl protons, protons of the repeating methylene units, and protons of the methylene group $\beta$ to the carbonyl group, respectively $[30,31]$. The signal at $2.0 \mathrm{ppm}$ was attributed to allylic methylene protons while the signal at $2.7 \mathrm{ppm}$ was assigned to the bisallylic methylene protons. The peak at $2.3 \mathrm{ppm}$ was assigned to protons of the methylene group $\alpha$ to the carbonyl group while the peak at $5.3 \mathrm{ppm}$ was considered to be the signal of the olefinic protons. The signal at $3.5 \mathrm{ppm}$ in the esterified oil suggested the conversion of the free fatty acids in the oil to methyl esters. The signal appearing at around 4.1$4.3 \mathrm{ppm}$ was assigned to glyceridic methylene protons. This signal at 4.1-4.3 ppm was seen only in the oil and the esterified oil; the peak disappeared after transesterification indicating the conversion of the esterified oil to biodiesel. An intense signal was also found at $3.7 \mathrm{ppm}$ in the biodiesel which was attributed to the protons of the methoxyl group of the biodiesel indicating a high conversion of the oil into biodiesel after the transesterification reaction.

Figure 3 shows the ${ }^{13} \mathrm{CNMR}$ of the oil, esterified oil, and biodiesel. The signals at around $\delta 60.30,62.10$, and 69.20 in the ${ }^{13} \mathrm{CNMR}$ spectra of the oil and esterified oil revealed the presence of glyceryl carbon atoms in the triglyceride molecules. The spectrum of the esterified oil also showed a signal of low intensity at $\delta 51.42$ (E) which supports the result of the ${ }^{1} \mathrm{HNMR}(3.5 \mathrm{ppm})$ indicating the conversion of the free fatty acids in the oil to methyl esters. Disappearance 


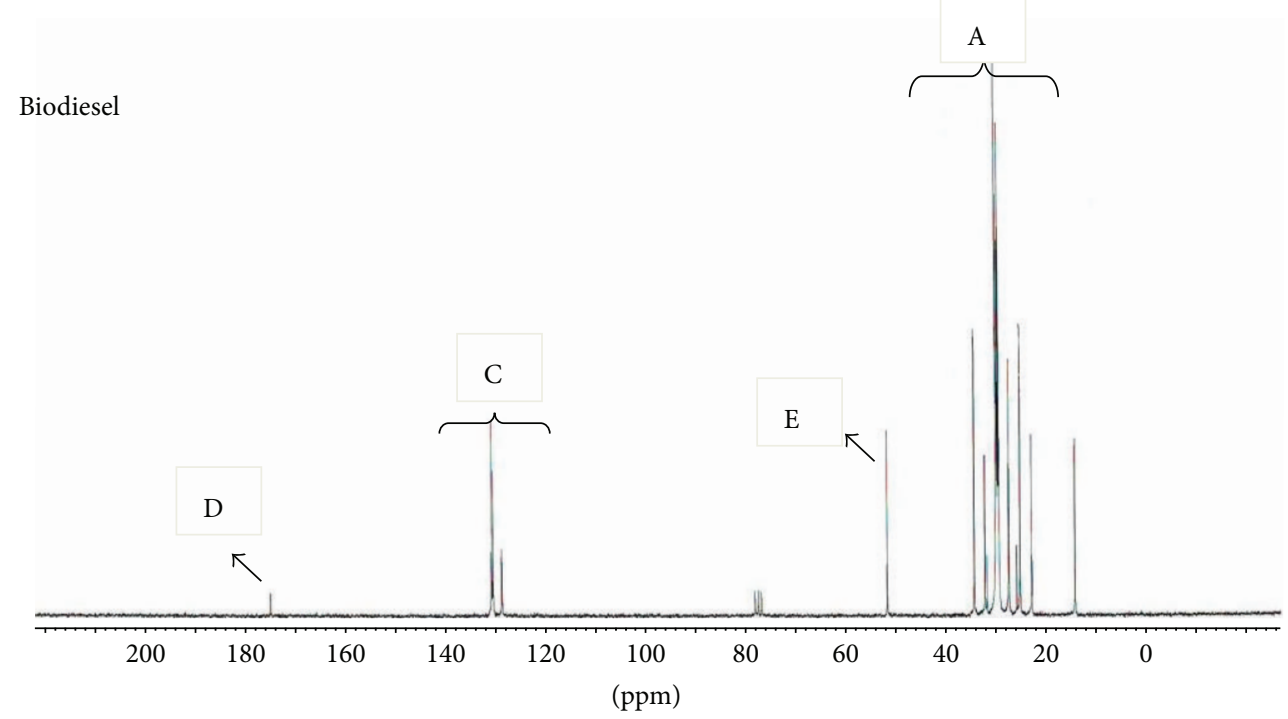

(a)

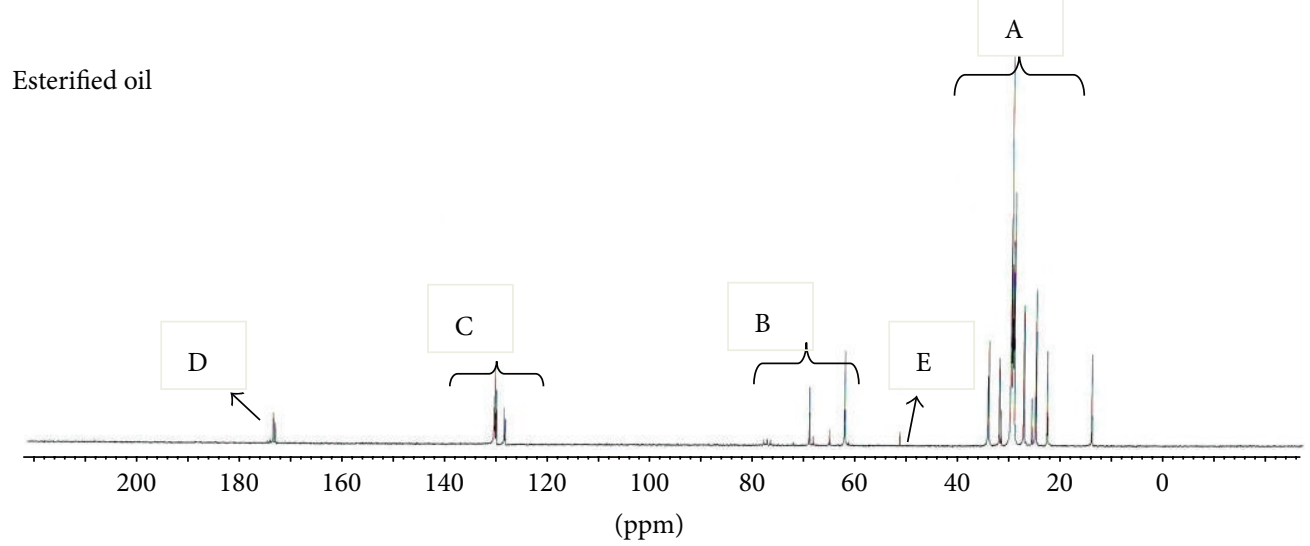

(b)

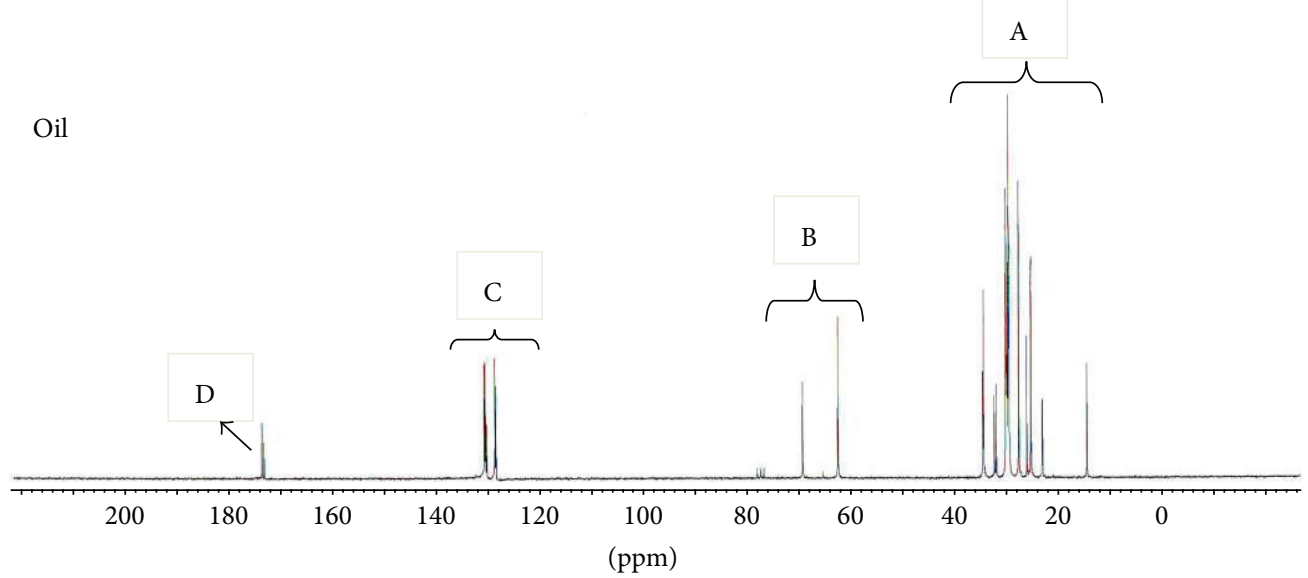

(c)

FIGURE $3:{ }^{13} \mathrm{CNMR}$ of oil, esterified oil, and biodiesel. A = methylene and methyl carbons, $\mathrm{B}=$ methylene and methine carbons of glycerine moiety, $\mathrm{C}=$ olefinic carbon, $\mathrm{D}=$ carbonyl carbon, and $\mathrm{E}=$ methoxy carbon. 
TABle 3: Fuel properties of biodiesel from the oil of Hura crepitans.

\begin{tabular}{lcc}
\hline Parameters & Hura crepitans & EN recommendation \\
\hline Ester $(\mathrm{wt} \%)$ & $98.70 \pm 0.40$ & 96.50 \\
Acid value $(\mathrm{mg} \mathrm{KOH} / \mathrm{g})$ & $0.21 \pm 0.00$ & 0.60 \\
Iodine value $(\mathrm{g}$ iodine/100 g) & $119.50 \pm 0.50$ & 120 \\
Triglyceride $(\mathrm{wt} \%)$ & $0.10 \pm 0.05$ & 0.20 \\
Diglyceride $(\mathrm{wt} \%)$ & $0.13 \pm 0.05$ & 0.20 \\
Monoglyceride $(\mathrm{wt} \%)$ & $0.30 \pm 0.10$ & 0.80 \\
Copper corrosion test & $1 \mathrm{~A}$ & $1 \mathrm{~A}$ \\
Flash point $\left({ }^{\circ} \mathrm{C}\right)$ & $152 \pm 1.10$ & 120 \\
Oxidative stability $(\mathrm{h})$ & $6.82 \pm 0.80$ & 6 \\
Viscosity $\left(\mathrm{mm}^{2} / \mathrm{s}\right)$ & $3.95 \pm 0.20$ & $3.50-5.00$ \\
Cetane number & $45.62 \pm 0.30$ & 51 \\
Density $\left(\mathrm{g} \mathrm{cm}{ }^{-3}\right.$ ) & $0.86 \pm 0.02$ & $0.86-0.90$ \\
Calorific value $(\mathrm{m} / \mathrm{kg})$ & $39.10 \pm 0.30$ & - \\
\hline
\end{tabular}

Values are mean \pm standard deviation of triplicate determinations.

of the glyceryl carbon signals (B) in the biodiesel spectrum and appearance of new signal at $\delta 51.60$ (E) due to methoxy carbon are indicative of the formation of biodiesel.

3.3. Properties of the Biodiesel. The determined properties of the biodiesel are shown in Table 3. However, the peak at $2.3 \mathrm{ppm}$ which was assigned to the protons of the methylene group $\alpha$ to the carbonyl group $\left(\mathrm{CH}_{3} \mathrm{O}-\mathrm{CO}-\mathrm{CH}_{2}-\mathrm{CH}_{2}-\right)$ and the prominent peak at $3.7 \mathrm{ppm}$ attributed to the methoxy protons $\left(-\mathrm{CH}_{2}-\mathrm{OC}-\mathrm{OCH}_{3}\right)$ were used in the determination of $\%$ yield according to

$$
\% \text { Yield }=100 \times \frac{2\left(\mathrm{~A}_{\mathrm{ME}}\right)}{3\left(\mathrm{~A}_{\alpha-\mathrm{CH}_{2}}\right)} .
$$

$\mathrm{A}_{\mathrm{ME}}$ is the integration value of the protons of the methoxy $\left(-\mathrm{CO}_{2} \mathrm{CH}_{3}\right)$, the strong singlet peak at around $3.7 \mathrm{ppm}$, and $\mathrm{A}_{\alpha-\mathrm{CH}_{2}}$ is the integration value of the methylene protons adjacent to the methyl ester moieties $\left(-\mathrm{CH}_{2} \mathrm{CO}_{2} \mathrm{CH}_{3}\right)$, the peak at around $2.3 \mathrm{ppm}$. The factors 2 and 3 were derived from the fact that the methylene carbon possesses two protons and the alcohol (methanol derived) carbon has three attached protons [32]. Using the integral values of these two peaks, a yield of $98.70 \pm 0.40 \%$ was obtained which was confirmed using column chromatography [23]; this value was higher than values reported for biodiesel produced from sunflower and soyabean oil [33]. The initial acid value of the oil was $4.41 \pm 0.20 \mathrm{mg} \mathrm{KOH} / \mathrm{g}$ but this value was reduced to $0.11 \pm 0.00 \mathrm{mg} \mathrm{KOH} / \mathrm{g}$ after the one-step pretreatment of $2 \%$ sulphuric acid in methanol which amounted to an efficiency of $97.51 \%$ according to (1) above. Viscosity is an important property of diesel fuels which reflects the operation of fuel injection from the diesel injector, flow in fuel pumps, and pipelines especially at low temperatures [34]; the value of viscosity for Hura crepitans biodiesel was found to be $3.95 \pm$ $0.2 \mathrm{~mm}^{2} / \mathrm{s}$. Density also influences the injection performance of fuel as a high density for biodiesel will result in the delivery of a slightly greater mass of fuel [35]; it was found to be $0.86 \pm 0.02 \mathrm{~kg} / \mathrm{cm}^{3}$ which is lower than what has been reported for sunflower, soyabean, and rapeseed oil suggesting better performance than those from the previous study. The iodine value and the calorific value were found to be $119.50 \pm 0.50 \mathrm{~g}$ iodine $/ 100 \mathrm{~g}$ and $39.10 \pm 0.30 \mathrm{~mJ} / \mathrm{kg}$, respectively. Normal modern highway diesels run best with a cetane number fuel rates between 45 and 55; in the present study the cetane number was found to be $45.62 \pm 0.30$. The results of the tri-, di-, and monoacylglycerol as well as the flash point and copper corrosion tests are in agreement with the recommended values by EN 14214.

One important problem associated with renewable fuel derived from vegetable oil and animal fats is poor oxidative stability. This is especially true for unsaturated seed oil-based biodiesel which has significantly higher levels of polyunsaturation. The Rancimat method (Rancimat EN 14112) expresses the oxidation stability of the tested material in terms of an induction period for the production of volatile organic acids, which are byproducts of fatty acid ester oxidative degradation with heat and oxygen. A minimum Rancimat induction period of $6 \mathrm{~h}$ is defined for biodiesel samples within UNE EN14214 and the oxidative stability of biodiesel from Hura crepitans was found to be $6.82 \pm 0.80 \mathrm{~h}$ which is lower than value reported for sunflower and that of the recommended value. This value indicated good stability of the biodiesel from Hura crepitans which also corresponds to the period of time required for the biodiesel to degrade at $110^{\circ} \mathrm{C}$ under a constant air stream to such an extent that the formation of volatile acids can be recorded through a conductivity increase.

\section{Conclusions}

The seed of Hura crepitans is a good source of oil. The oil extracted from the seed of Hura crepitans was analyzed for iodine value, saponification value, and free fatty acid content. The oil was later subjected to the production of biodiesel using two-step reaction system involving a first step of pretreatment via esterification reaction and a second step via transesterification reaction. The pretreatment step showed that free fatty acid in seed oil can be reduced in a one-step 
pretreatment of esterification using $\mathrm{H}_{2} \mathrm{SO}_{4}$ as catalyst with an efficiency of $97.51 \%$. The process gave a biodiesel yield of $98.70 \pm 0.40 \%$ with properties within the recommended values of EN 14214.

\section{Conflict of Interests}

The authors declare that there is no conflict of interests regarding the publication of this paper.

\section{Acknowledgments}

The authors are grateful to the Department of Chemistry, University of Ibadan, Nigeria, and Indian Institute of Chemical Technology, Hyderabad, India, for allowing the use of equipment. The authors also appreciate the support of Department of Physical Chemistry, Technical University of Dresden, Dresden, Germany.

\section{References}

[1] M. K. Lam, K. T. Lee, and A. R. Mohamed, "Sulfated tin oxide as solid superacid catalyst for transesterification of waste cooking oil: an optimization study," Applied Catalysis B, vol. 93, no. 1-2, pp. 134-139, 2009.

[2] A. Bouaid, M. Martinez, and J. Aracil, "Long storage stability of biodiesel from vegetable and used frying oils," Fuel, vol. 86, no. 16, pp. 2596-2602, 2007.

[3] N. S. Babu, R. Sree, P. S. S. Prasad, and N. Lingaiah, "Roomtemperature transesterification of edible and nonedible oils using a heterogeneous strong basic $\mathrm{Mg} / \mathrm{La}$ catalyst," Energy and Fuels, vol. 22, no. 3, pp. 1965-1971, 2008.

[4] M. M. Gui, K. T. Lee, and S. Bhatia, "Feasibility of edible oil versus non-edible oil versus waste edible oil as biodiesel feedstock," Energy, vol. 33, no. 11, pp. 1646-1653, 2008.

[5] M. K. Lam, K. T. Lee, and A. R. Mohamed, "Homogeneous, heterogeneous and enzymatic catalysis for transesterification of high free fatty acid oil (waste cooking oil) to biodiesel: a review," Biotechnology Advances, vol. 28, no. 4, pp. 500-518, 2010.

[6] L. Lin, Z. Cunshan, S. Vittayapadung, S. Xiangqian, and D. Mingdong, "Opportunities and challenges for biodiesel fuel," Applied Energy, vol. 88, no. 4, pp. 1020-1031, 2011.

[7] G. R. Quick, "Developments in use of vegetable oil as fuel for diesel engines," ASAE Paper no. 80-1525R, ASAE, St. Joseph, Mich, USA, 1980.

[8] C. L. Peterson, R. O. Cruz, L. Perkings, R. Korus, and D. L. Auld, "Transesterification of vegetable oil for use as diesel fuel," A Progress Report ASAE Paper No. PNWS90-610, ASAE, St. Joseph, Mich, USA, 1990.

[9] R. A. Korus, D. S. Hoffman, N. Bam, C. L. Peterson, and C. D. Drown, "Transesterification process to manufacture ethyl ester of rape oil," Tech. Rep., Department of Chemical Engineering, University of Idaho, Moscow, Idaho, USA, 1995.

[10] G. Kafuku and M. Mbarawa, "Effects of biodiesel blending with fossil fuel on flow properties of biodiesel produced from nonedible oils," International Journal of Green Energy, vol. 7, no. 4, pp. 434-444, 2010.

[11] F. Ma and M. A. Hanna, "Biodiesel production: a review," Bioresource Technology, vol. 70, no. 1, pp. 1-15, 1999.
[12] G. Knothe and K. R. Steidley, "Kinematic viscosity of biodiesel fuel components and related compounds: influence of compound structure and comparison to petrodiesel fuel components," Fuel, vol. 84, no. 9, pp. 1059-1065, 2005.

[13] M. Singh, "Economics of biofuels for the transport sector in South Africa," Energy for Sustainable Development, vol. 10, no. 2, pp. 40-47, 2006.

[14] D. H. Scarisbrook and A. J. Ferguson, New Horizons for Oilseed Rape, Semundo, Cambridge, UK, 1995.

[15] M. A. Fowomola and A. A. Akindahunsi, "Nutritional quality of sandbox tree (Hura crepitans Linn.)," Journal of Medicinal Food, vol. 10, no. 1, pp. 159-164, 2007.

[16] J. A. O. Oyekunle, A. A. Omode, and J. O. Akinnifesi, "Physical properties of oils extracted from some Nigerian nonconventional oilseeds," Journal of Applied Sciences, vol. 7, no. 6, pp. 835-840, 2007.

[17] A. Adewuyi, A. Göpfert, T. Wolff, B. V. S. K. Rao, and R. B. N. Prasad, "Synthesis of azidohydrin from Hura crepitans seed oil: a renewable resource for oleochemical industry and sustainable development," ISRN Organic Chemistry, vol. 2012, Article ID 873046, 7 pages, 2012.

[18] O. G. Igbum, A. C. Eloka-Eboka, and C. A. Nwadinigwe, "Effects of transesterification variables on yields and properties of biodiesel fuels produced from four virgin tropical seeds oils," International Journal of Environmental Bioenergy, vol. 1, pp. 119130, 2012.

[19] A. Adewuyi, R. A. Oderinde, and I. A. Ajayi, "Kinetics of the effect of bleaching on the characterization, mineralnutrients and fat soluble vitamins of Blighia unijugata bak seed oil," Rivista Italiana delle Sostanze Grasse, vol. 86, no. 3, pp. 199-208, 2009.

[20] AOAC, Official Methods of Analysis, vol. 67, Association of Official Analytical Chemist, Arlington, Va, USA, 14th edition, 1984.

[21] G. Corro, N. Tellez, T. Jimenez, A. Tapia, and F. Banuelos, "Biodiesel from waste frying oil. Two step process using acidified $\mathrm{SiO}_{2}$ for esterification step," Catalysis Today, vol. 166, no. 1, pp. 116-122, 2011.

[22] American Society for Testing and Material (ASTM), "Standard test method for kinetic viscosity of transparent and opaque liquids," pp. 1-3, Conshohocken, Pa, USA, 1998.

[23] AOCS, "American Oil Chemists' Society official method for the quantitative separation of monoglycerides, diglycerides and triglycerides by silica gel column chromatography," Cd 11c-93, 2003.

[24] K. Krisnangkura, "A simple method for estimation of Cetane index of vegetable oil methyl esters," JAOCS: Journal of the American Oil Chemists' Society, vol. 63, no. 4, pp. 552-553, 1986.

[25] W. Batel, M. Graef, G. J. Meyer, R. Moller, and F. Schoedder, "Pflonzenole fur die Kraftstoff-und Energieversorgung," Grundlagen der Landtechnik, vol. 30, pp. 40-51, 1980.

[26] European Committee for Standardization, EN 14112: Fat and Oil Derivatives -Fatty Acid Methyl Esters (FAME)_Determination of Oxidation Stability (Accelerated Oxidation Test), European Committee for Standardization, Brussels, Belgium, 2003.

[27] American Society for Testing and Material (ASTM), Copper Strip Corrosion Test D396 Specification for Fuel Oils, 2004.

[28] AOCS, “American Oil Chemists' Society official method for flash point closed cup method (Modified closed cup method, ASTM designation D 93-80)," Cc 9b-55, USA, 1997. 
[29] L. H. Princen and J. A. Rothfus, "Development of new crops for industrial raw materials," Journal of the American Oil Chemists' Society, vol. 61, no. 2, pp. 281-289, 1984.

[30] F. D. Gunstone, Oils and Fats in the Food Industry: Food Industry Briefing Series, Blackwell, London, UK, 2008.

[31] M. Tariq, S. Ali, F. Ahmad et al., "Identification, FT-IR, NMR $\left({ }^{1} \mathrm{H}\right.$ and $\left.{ }^{13} \mathrm{C}\right)$ and $\mathrm{GC} / \mathrm{MS}$ studies of fatty acid methyl esters in biodiesel from rocket seed oil," Fuel Processing Technology, vol. 92, no. 3, pp. 336-341, 2011.

[32] G. Knothe, J. van Gerpen, and J. Krahl, Biodiesel Handbook, American Oil Chemists' Society Press, Champaign, Ill, USA, 2005.

[33] C. Bindhu, J. R. C. Reddy, B. V. S. K. Rao et al., "Preparation and evaluation of biodiesel from sterculia foetida seed oil," Journal of the American Oil Chemists' Society, vol. 89, no. 5, pp. 891-896, 2012.

[34] L. C. Meher, D. Vidya Sagar, and S. N. Naik, “Technical aspects of biodiesel production by transesterification-a review," Renewable and Sustainable Energy Reviews, vol. 10, no. 3, pp. 248-268, 2006.

[35] A. Demirbas, "Biodiesel production via non-catalytic SCF method and biodiesel fuel characteristics," Energy Conversion and Management, vol. 47, no. 15-16, pp. 2271-2282, 2006. 


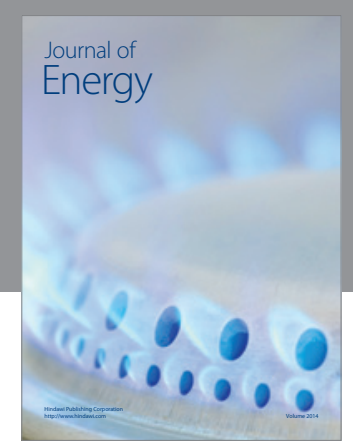

Journal of

Industrial Engineering
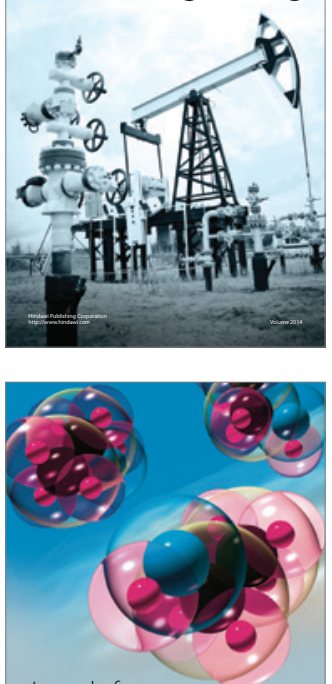

Fuels
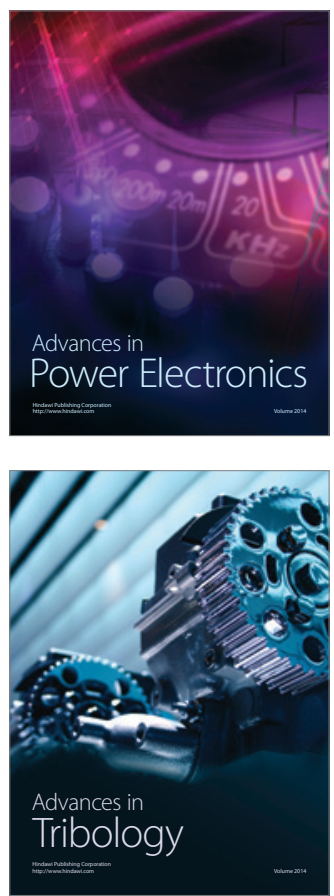

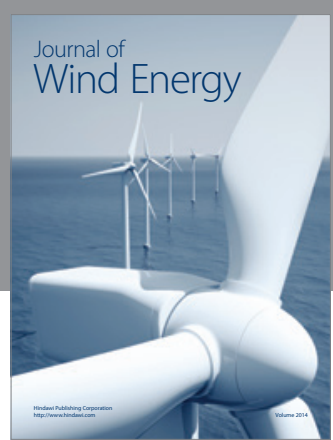

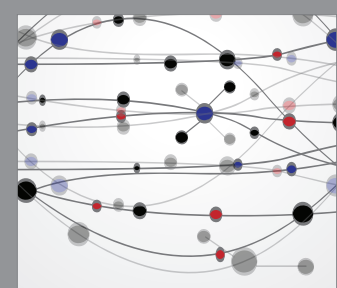

The Scientific World Journal

Submit your manuscripts at http://www.hindawi.com

Journal of

Structures
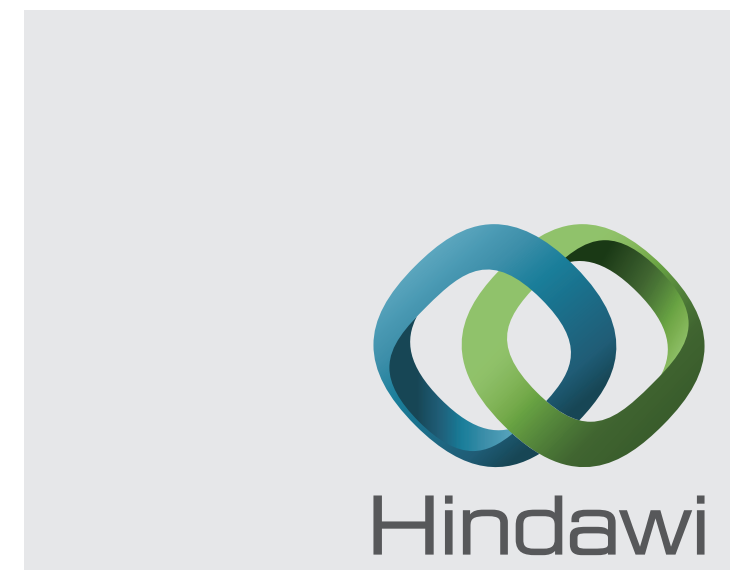

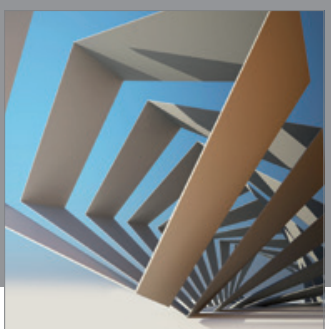

Rotating

Machinery
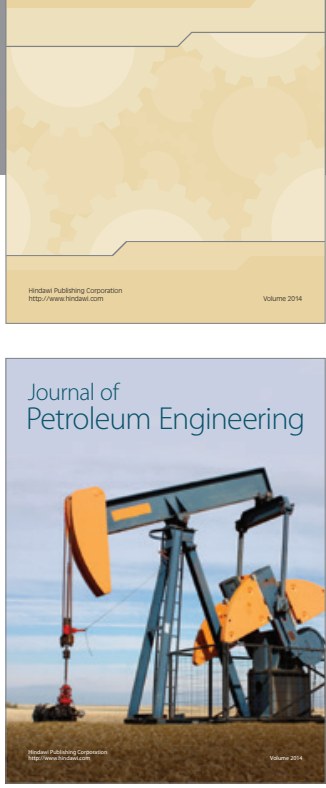

Journal of

Solar Energy
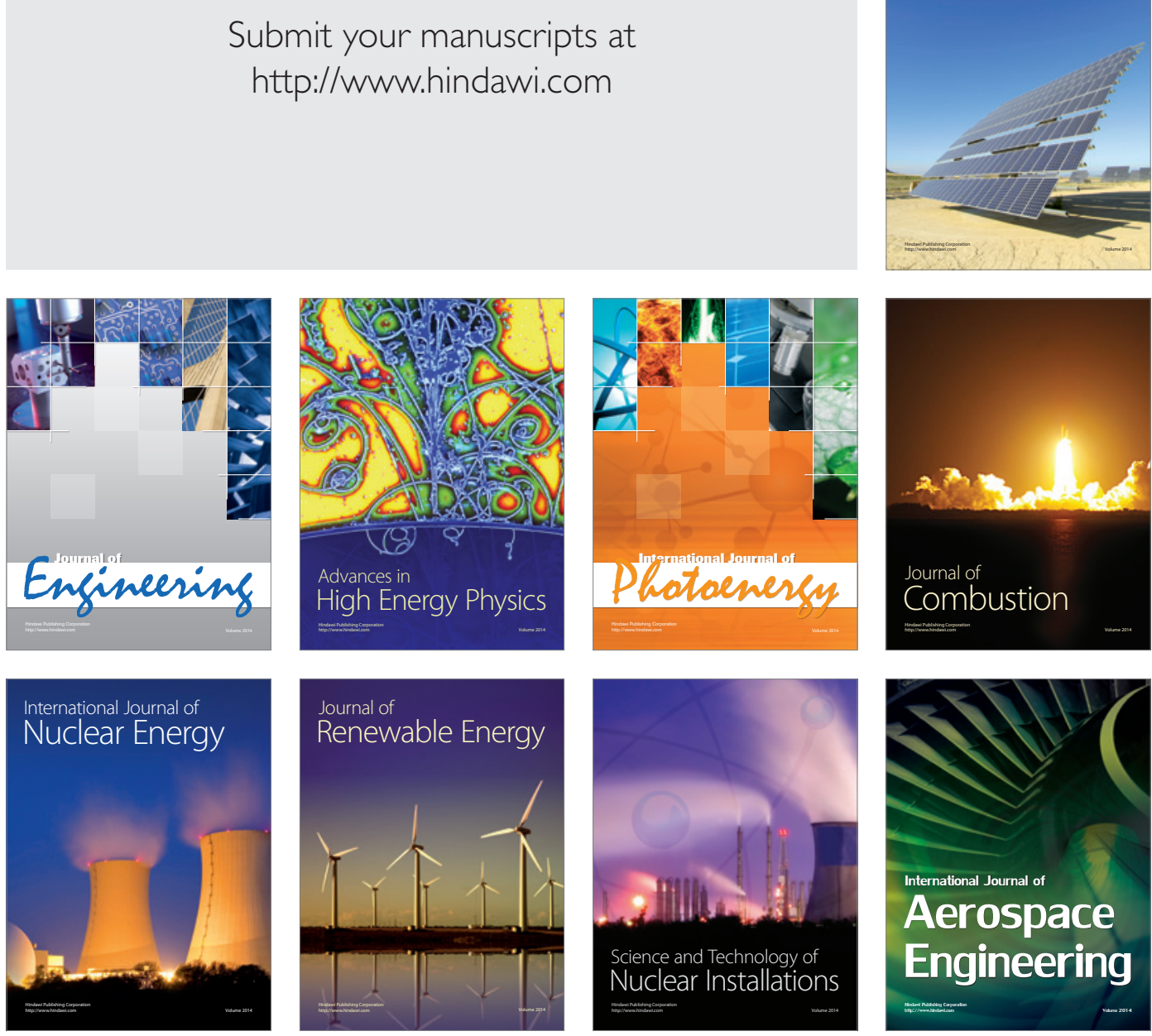